\title{
INTERNACIONALIZAÇÃO DE UMA EMPRESA DE TURISMO VOLUNTÁRIO PELA LÓGICA EFFECTUATION
}

Vitor Pires Dos Santos ${ }^{1}$

Renato Dourado Cotta De Mello ${ }^{1}$

Daniel Kamlot ${ }^{2}$

\footnotetext{
${ }^{1}$ COPPEAD / Universidade Federal do Rio de Janeiro

${ }^{2}$ Escola Superior de Propaganda e Marketing/ESPM-Rio
} 


\section{INTERNACIONALIZAÇÃO DE UMA EMPRESA DE TURISMO VOLUNTÁRIO PELA LÓGICA EFFECTUATION}

Resumo: O presente estudo visa examinar, sob a ótica da lógica effectuation, o processo de criação e internacionalização de uma empresa brasileira de turismo de voluntariado social, identificando e compreendendo a operacionalização da estratégia relacionada. A metodologia utilizada se baseou na pesquisa qualitativa, com a utilização de estudo de caso único. Os resultados obtidos permitem observar que a empresa se utilizou da lógica Effectuation para criar e internacionalizar seus negócios. Fatores como o perfil e o conhecimento dos sócios, aliados à capacidade de estabelecer parcerias e explorar oportunidades com poucos recursos, reforçam a utilização da lógica em questão. A sua competitividade vem da criação de um negócio inovador com imediata orientação internacional e da oferta de serviços que exploram conhecimento, experiência e fazer o bem. $\mathrm{O}$ estudo pretende contribuir para a compreensão do processo de internacionalização do serviço de turismo voluntário, identificando dimensões que transformaram a empresa estudada em um caso singular do segmento.

Palavras-chave: Effectuation. Internacionalização. Turismo Voluntário. Empreendedorismo.

\section{Introdução}

A utilização de ferramentas gerenciais tradicionais, como planos estratégicos e análise de cenários, mesmo que feitos de forma convencional (MEYER; ROWAN, 1977), auxilia no entendimento de alguns fenômenos referentes à visão clássica de causalidade e decisão racional dos empreendedores ou gestores. A distância entre discurso e prática gerencial tem, ao menos em parte, fundamentos em alguns conceitos difundidos amplamente por escolas de negócios e consultorias pelo mundo, em que a tomada de decisão é analisada como um processo racional, com características lógicas e sequenciais.

No entanto, Sarasvathy (2001a) aponta que grande parte das teorias gerenciais pressupõe a existência de artefatos (indústrias, mercados, empresas etc.), a partir dos quais um decisor racional realizará análises de causa-efeito, análises de cenários e tomará decisões calculadas a partir de várias opções que se apresentem. Na prática corporativa, bem como em muitos trabalhos de estratégia e empreendedorismo, a lógica da análise (PORTER, 1980) se sobrepõe à lógica da criação de artefatos (KUZNETS; MURPHY,1966).

De acordo com Sarasvathy (2001a), a lógica prática de muitos empreendedores ao criar e desenvolver suas empresas era muito diferente da lógica descrita como racional nas teorias vigentes. Tal lógica, nomeada "causation", apoiava-se em previsões para calcular riscos e retornos ao fazer investimentos, e seus processos iniciavam ao se objetivar um dado efeito e buscar os meios para criá-lo. O objetivo a atingir, ou decisão a tomar, eram bem estruturados e específicos, e o critério para seleção dos meios era a maximização do retorno.

No ambiente de incertezas em que as empresas são criadas e se desenvolvem, surge a necessidade de utilização de uma abordagem diferente, capaz de entender o modo pelo qual, na prática, os empreendedores tomam suas decisões estratégicas. Esse modo seria a lógica do effectuation, entendida como o inverso da causalidade (SARASVATHY, 2001b).
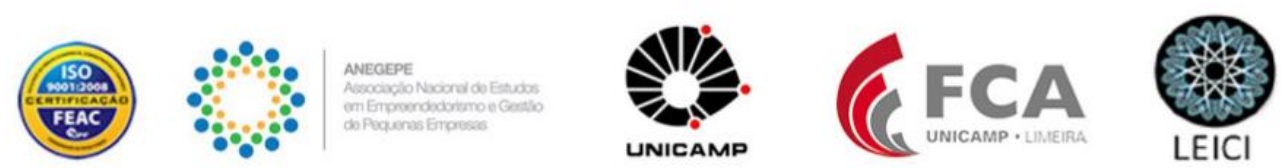
Para Sarasvathy (2001a, 2001b), effectuation é uma lógica que consiste em tomar decisões a partir de escolhas entre os efeitos que podem ser produzidos de um dado conjunto de meios, eliminando, consequentemente, a premissa de objetivos pré-existentes.

O turismo é uma atividade cada vez mais importante para o desenvolvimento econômico de diversas localidades pelo mundo. Simultaneamente, o trabalho voluntário vem crescendo e, cada vez mais, atraindo mais participantes. Integrando essas duas dimensões, temos o surgimento de um novo fenômeno, intitulado turismo voluntário. Esta atividade tem atraído cada vez mais participantes, que buscam novas experiências, a oportunidade de conhecer novos locais, novas culturas, ao mesmo tempo em que se pratica um ato solidário e humanitário (MCGEHEE, N. G.; CLEMMONS, 2008). Esses trabalhos sociais podem incluir atividades com idosos, crianças, fauna ou flora de uma localidade, participar de projetos sociais ou ecológicos, sendo possível vivenciar novos aprendizados e contato direto as pessoas que residem na região.

O turismo voluntário pode ser definido como um tipo de experiência turística oferecida por uma empresa de viagens aos viajantes como uma excursão opcional (alternativa), que contempla uma atividade de cunho voluntário, que proporciona a realização de uma troca de cultura com os moradores da localidade (GROSS, M. J; BROWN, G., 2008); ou, ainda, como a utilização do tempo livre em uma viagem para dar assistência a outros que necessitem (MCGEHEE, N. G.; CLEMMONS, 2008).

Para este estudo, emerge a seguinte pergunta de pesquisa: qual o papel da lógica effectuation no processo de criação e internacionalização da empresa Volunteers Vacations? Diante dessa questão, o presente artigo busca compreender e tecer considerações sobre o processo de internacionalização de uma empresa brasileira criada para proporcionar capacitação técnica empreendedora e promover experiências sociais por meio do serviço de turismo voluntário à luz de proposições teóricas que versam sobre o fenômeno da internacionalização de empresas, mais especificamente a lógica effectuation (SARASVATHY, 2001a).

O artigo foi organizado em seis seções, como segue: além desta introdução, constrói-se o referencial teórico na seção 2 , que discorre sobre a teoria que aborda os conceitos de oportunidade, oportunidade internacional, identificação e exploração de oportunidades internacionais; na seção 3, descreve-se a metodologia de pesquisa utilizada; na seção 4 expõese o caso da empresa e a sua análise à luz do referencial teórico; e, por fim, na seção 5, são feitas as considerações finais.

\section{Referencial Teórico}

Na medida em que cresce o interesse pelo empreendedorismo como campo de estudos, novas perspectivas teóricas têm surgido para tentar explicar as ações e as lógicas que direcionam o comportamento dos empreendedores (FISHER, 2012). Nesse contexto, duas abordagens ganham destaque em termos de utilização pelos empreendedores, a abordagem causation e a abordagem effectuation. A abordagem causation é embasada na análise e planejamento, enquanto a abordagem effectuation, se refere a estratégias emergentes e não preditivas (CHANDLER et al., 2011).

Segundo Sarasvathy (2001), o raciocínio causal é aquele ensinado na maioria das escolas de negócios do mundo (SARASVATHY, 2001b). Essas escolas dão subsídios para o

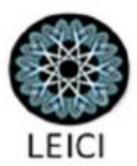


aprendizado de tomadas de decisões econômicas e gerenciais, por exemplo. No entanto, esses subsídios são orientados para empresas, mercados e economias já existentes (SARASVATHY, 2001a). Fisher (2012) acrescenta que o ambiente desses mercados é considerado estável e linear, tornando-os mensuráveis ou relativamente previsíveis. Assim, a busca sistemática por informações, a definição prévia dos objetivos e o estabelecimento de planos são favorecidos.

A abordagem causal possui um elemento importante: a elaboração de um plano de negócios, que consiste em um documento que descreve os estados atual e futuro da organização. A elaboração desse plano é uma atividade racional, que visa a auxiliar empreendedores a obterem maiores lucros, seja pela projeção de ganhos e eficiência, seja pela projeção do aumento de venda (HONIG; KARLSSON, 2004).

A tomada de decisões racionais do empreendedor baseia-se, principalmente, em dois fatores: nas informações relevantes disponíveis e na expectativa de retorno oferecida por cada opção identificada e analisada (CHANDLER et al., 2011). Após uma análise do ambiente, o empreendedor deve escolher entre as possibilidades de projetos disponíveis. Seguindo esse conceito, o processo empreendedor (no raciocínio causal) é constituído por três funções principais: a descoberta de uma oportunidade, a procura de recursos para o projeto e a realização dos benefícios por meio da implantação do projeto (CASSON; WADESON, 2007).

A lógica do causation começa com um objetivo e meios para alcançá-lo. Busca-se identificar a alternativa mais eficiente de se alcançá-lo. Para Fischer (2012), na lógica causal: o resultado e os meios são dados; existe uma seleção entre meios para alcançar esse resultado. Inicia-se pelos fins, realiza-se análise das expectativas de retorno, utiliza-se do princípio das perdas aceitáveis, são desenvolvidas análises competitivas e o controle do futuro.

A lógica effectuation se relaciona com a exploração de oportunidades em novos mercados com alto grau de incerteza, favorecendo um processo experimental e um aprendizado interativo que propicia ao empreendedor descobrir informações sobre o futuro, considerando o dinamismo do ambiente, sendo o futuro imprevisível e não mensurável (FISHER, 2012).

Sarasvathy (2001) acredita que, para explorar situações conhecidas, dependentes do efeito produzido, os processos causais são excelentes. No entanto, quando se trata da exploração de contingências dependentes do ator, o processo effectuation cumpre melhor a tarefa. Essa lógica transforma, continuamente, realidades existentes em possíveis mercados ao produzir oportunidades (SARASVATHY et al., 2003) e, ainda, o produto final é imprevisível. Os atores, a partir de seus meios, experiências e parcerias, à luz das contingências, fazem essa construção (READ; SARASVATHY, 2005).

Frese (2009) destaca que o empreendedor que se utiliza da lógica effectuation busca encontrar as melhores combinações dos meios que possui, como habilidades, recursos financeiros, materiais e acesso aos mercados, entre outros.

Depreende-se, portanto, que na lógica effectuation, é a partir dos meios dados, ou seja, dos recursos que estão disponíveis ao empreendedor, pertencentes a ele ou a terceiros de sua rede de relacionamentos, que serão desenvolvidas estratégias para alcançar os objetivos.

Os novos empreendimentos possuem a tendência de seguir a lógica effectuation nos seus estágios iniciais de seus ciclos de vida, visto que as incertezas do negócio e do mercado são bem maiores do que quaisquer metodologias de previsão eficientes de curto ou médio prazos (SARASVATHY, 2001a).

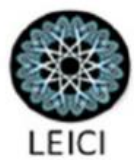


Fisher (2012) apresenta uma visão comparativa entre essas abordagens, representada no Quadro 1.

\begin{tabular}{|c|c|c|}
\hline & 1. Causation & 2. Effectuation \\
\hline $\begin{array}{l}\text { Quais fatores explicam a } \\
\text { abordagem? }\end{array}$ & $\begin{array}{l}\text { - O Resultado é dado. } \\
\text { - Seleção entre meios para } \\
\text { alcançar esse resultado: } \\
\text { 1. Começo pelos fins. } \\
\text { 2. Análise das expectativas de } \\
\text { retorno. } \\
\text { 3. Análise competitiva. } \\
\text { 4. Controle do Futuro. }\end{array}$ & 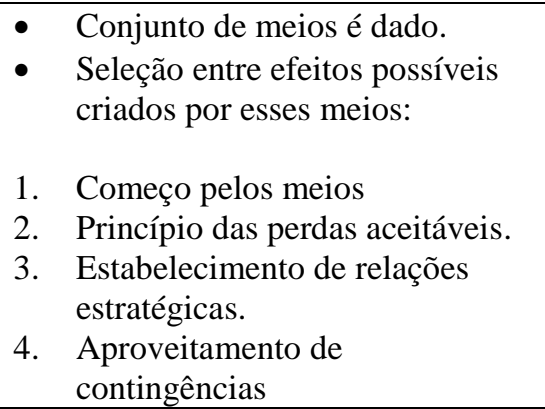 \\
\hline $\begin{array}{l}\text { Como os fatores } \\
\text { identificados se } \\
\text { relacionam com a busca } \\
\text { por resultados? }\end{array}$ & $\begin{array}{l}\text { Processos causation }>>\text { Identificam e } \\
\text { exploram oportunidades em } \\
\text { mercados existentes com baixo nível } \\
\text { de incerteza. } \\
\text { - Participantes posteriores em uma } \\
\text { indústria >> Processos de } \\
\text { causalidade. }\end{array}$ & $\begin{array}{l}\text { Processos de effectuation }>> \\
\text { Identificam e exploram } \\
\text { oportunidades em novos mercados } \\
\text { com altos níveis de incerteza. } \\
\text { - } \quad \text { Operadores de início bem } \\
\text { sucedidos em uma nova indústria } \\
\text { >> processo de effectuation. } \\
\text { - As falhas precoces podem ser } \\
\text { mais baratas. }\end{array}$ \\
\hline $\begin{array}{l}\text { Por que essas relações } \\
\text { entre os fatores e os } \\
\text { resultados existem? }\end{array}$ & $\begin{array}{l}\text { A teoria da decisão: } \\
\text { Os tomadores de decisão lidam com } \\
\text { futuro mensurável ou previsível. }\end{array}$ & $\begin{array}{l}\text { Os tomadores de decisão lidam com } \\
\text { fenômenos imprevisíveis e vão reunir } \\
\text { informações através de técnicas } \\
\text { experimentais e interativas, } \\
\text { destinadas a descobrir o futuro da } \\
\text { aprendizagem. }\end{array}$ \\
\hline $\begin{array}{l}\text { Quem, Onde e Quando } \\
\text { as afirmações e limitações } \\
\text { acerca da teoria. }\end{array}$ & $\begin{array}{l}\text { Ambiente estático, linear. } \\
\text { - Aspectos previsíveis de um } \\
\text { futuro incerto são identificáveis e } \\
\text { mensuráveis. } \\
\text { - Oportunidades empresariais são } \\
\text { objetivas e identificáveis } a \\
\text { priori. }\end{array}$ & $\begin{array}{l}\text { Dinâmico não linear e ambientes } \\
\text { ecológicos. } \\
\text { - O futuro é desconhecido e não } \\
\text { mensurável. } \\
\text { - Oportunidades empreendedoras } \\
\text { são subjetivas, socialmente } \\
\text { construídas e criadas }\end{array}$ \\
\hline
\end{tabular}

\section{Quadro 1 - Diferenças entre Effectuation e Causation Fonte: adaptado de Fischer (2012, p.1022)}

Enquanto a lógica causal tradicional prega que o mercado possuiria algum tipo de necessidade específica e que esta é, consequentemente, atendida por uma empresa, a lógica effectuation parte do princípio de que as oportunidades vão sendo construídas à medida que são identificadas, e até, de certa forma, simultaneamente.

$\mathrm{O}$ olhar effectuation defende o dinamismo das relações, de forma que mitiga a importância de possíveis planejamentos e seleções prévias dessas relações. Com isso, enfatiza o caráter adaptativo da construção das mesmas, de forma não causal e camaleônica, moldandose à conjuntura que a empresa esteja, eventualmente, vivenciando. Outra questão teórica relevante é que, conforme afirma Andersson (2011), a teoria effectuation preocupar-se-ia, explicitamente, tanto com o indivíduo quanto com a firma. Isso daria a ela uma capacidade mais 
ampla de enxergar os problemas multifacetados que as empresas enfrentam no mundo atual, globalizado.

\subsection{Princípios e Processo de Effectuation}

No que se refere à abordagem do cliente, Wiltbank e Sarasvathy (2010) analisam e comparam duas diferentes óticas: (1) a do modelo clássico dos livros de marketing e (2) a dos pressupostos da lógica de effectuation utilizados por empreendedores experientes (Figura 1). Nesse sentido, a abordagem clássica dos livros de marketing definiria o processo decisório estratégico das empresas de forma oposta à teoria de effectuation. Após a realização de pesquisas e estudos minuciosos, a empresa define o mercado e estabelece a segmentação, público-alvo, posicionamento e estratégias de marketing que são baseadas na racionalidade preditiva, ou seja, as estratégias e ações são baseadas em previsões. Já a proposta de effectuation aplicado ao marketing lidaria com questões mais práticas, como, por exemplo, "Quem eu sou? O que eu sei? Quem eu conheço?”. Logo, a estratégia de marketing começa com a identificação do cliente ou de um possível parceiro local. A partir deste cliente, o empreendedor define um segmento de clientes com características similares e agrega ao longo do tempo novos segmentos de forma incidental e casual, para finalmente definir um mercado para seu produto ou serviço. Nessa abordagem, os recursos empresariais iniciais são escassos e o resultado final da estratégia de marketing surge a partir da interação com os stakeholders e da expansão da base de clientes, que acontece de maneira incidental.

A Figura 1, a seguir, sistematiza a diferença entre essas duas abordagens:

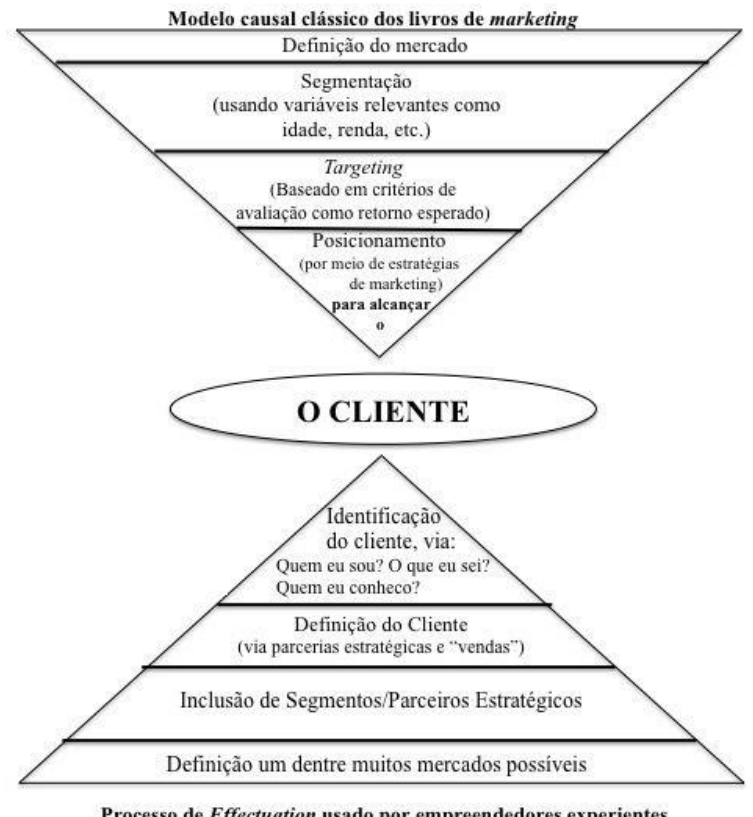

Figura 1 - Comparação entre modelo de segmentação e posicionamento clássico do Marketing e a teoria de Effectuation

Fonte: Adaptado de Wiltbank e Sarasvathy (2010, p.34).

A proposição effectuation é resumida por Sarasvathy (2001a, 2001b) por meio de cinco 
princípios:

a) Comece com os meios. Esse princípio envolve as diferentes utilizações dos meios de que o agente já dispõe, lembrando que estes já seriam dados, para a produção de diferentes efeitos. Sarasvathy (2001b) dividiu esses meios em três categorias: quem eles são (traços, gostos, habilidades), o que sabem (educação, treinamento, especialidade, experiência) e quem conhecem (social e profissionalmente). A partir desses meios, os empresários começam a imaginar possíveis efeitos que podem ser criados com eles (SARASVATHY et al., 2014).

b) Riscos acessíveis, em vez de retornos esperados: modelos baseados em causalidade baseiam-se na maximização do retorno potencial de uma decisão, selecionando estratégias ótimas (que otimizem a relação meios/retorno). No processo effectual, o tomador de decisão - o empreendedor, no caso - determina previamente um nível de perda aceitável e experimenta tantas estratégias quanto possíveis, dadas a limitada dotação de recursos disponíveis. Destaca-se que, ao avaliar as características desse princípio conjuntamente com o de perdas aceitáveis, é possível entender como empreendedores conseguiriam aplicar uma ideia em prática, utilizando uma quantidade de recursos limitados (SARASVATHY et al., 2014).

c) Formar parcerias, ao invés de análises competitivas: os modelos de causalidade, como o modelo de estratégia de Porter (1980), enfatizam análises competitivas detalhadas (em várias dimensões) sobre a competição em determinado mercado. O modelo effectual, por outro lado, enfatiza alianças estratégicas e pré-comprometimentos com stakeholders como uma forma de reduzir e/ou eliminar incertezas e construir barreiras que reduzam a competição num determinado mercado (diminuindo a concorrência).

d) Exploração de contingências, ao invés da utilização de conhecimento préexistente: quando o conhecimento pré-existente, tal como experiência pessoal ou o domínio de uma nova tecnologia, representa a principal fonte de vantagem competitiva, modelos de causalidade podem ser preferíveis. O modelo, entretanto, pode ser um processo mais apropriado para explorar contingências que surgem inesperadamente ao longo do tempo. A lógica do effectuation busca aproveitar a existência de incertezas como potenciais oportunidades a serem exploradas, em vez de pensá-las como fatores a serem previstos e contingenciados (TASIC, 2007; SARASVATHY et al., 2014).

e) Controlar um futuro imprevisível, ao invés de prever um futuro incerto: os processos decisórios baseados na causalidade se baseiam nos aspectos previsíveis de um futuro incerto. A lógica para usar os processos baseados na causalidade é: na medida em que podemos prever o futuro, podemos controlá-lo. Já, na lógica effectuation: na medida em que nós podemos controlar o futuro, não necessitamos prevê-lo.

\section{Processo de Effectuation}

O raciocínio adjacente à lógica effectuation, conforme apresentado na Figura 2, diferentemente da lógica causation, não começa com um objetivo específico, mas sim com determinados meios. A partir destes meios, os empreendedores começam a imaginar possíveis efeitos que podem ser criados com eles. Na maioria das vezes, eles começam com os meios que estão ao seu alcance e agem sem elaborar um plano. Os objetivos podem surgir contingencialmente, com o tempo, da imaginação variada e das diversas aspirações dos fundadores e das pessoas que interagem com eles. Essas interações com novos agentes resultam

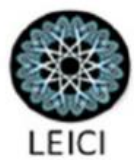


em comprometimentos com o empreendimento. Os novos parceiros agregam valor para o empreendimento, pois trazem um novo conjunto de meios e de objetivos. Sendo assim, cada novo comprometimento produz ciclos subsequentes de expansão (novos meios) e conversão (novos objetivos). Uma forma de entender tais ciclos seria que novos meios permitiriam uma reavaliação do processo de effectuation, o que levaria à citada expansão do ciclo; já novos objetivos produzem novas interações entre agentes no mercado, permitindo a exploração de oportunidades na forma representativa de um novo mercado (Figura 2).

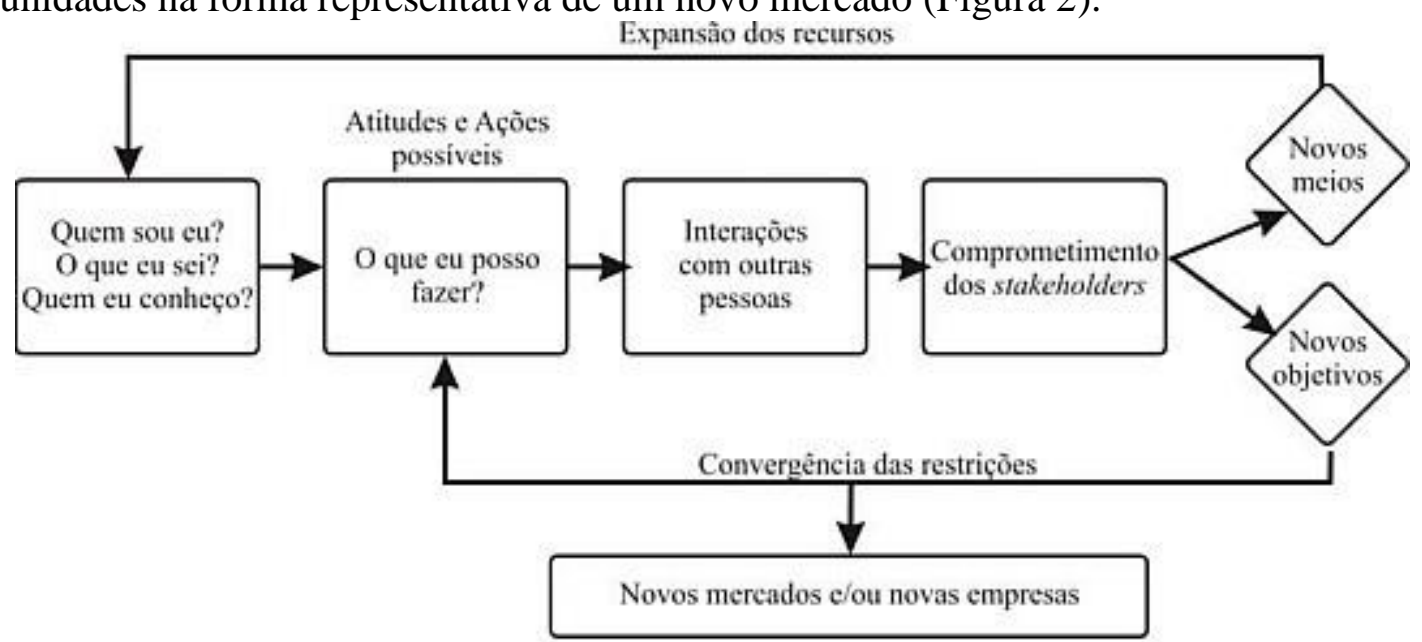

Figura 2 - Processo do Effectuation.

Fonte: adaptado de Read e Sarasvathy (2005, p.53)

\section{Metodologia da pesquisa}

Para a presente pesquisa, de caráter exploratório, optou-se por uma abordagem qualitativa, por meio de estudo de caso único. O presente trabalho de pesquisa seguiu as três etapas definidas por Dellagnelo e Silva (2005) e baseadas em Bardin (1994): em primeiro lugar, foi realizada uma pré-análise, que corresponde à preparação do processo, em que foram definidos os entrevistados, realizadas as entrevistas e as transcrições destas, além da organização da estrutura do trabalho. No segundo momento, foi analisado o material, com categorização dos temas a serem abordados no processo da verificação, entendendo-se estas categorias como elementos ou aspectos com características comuns ou que se relacionavam entre si. E, por fim, procedeu-se a interpretação, entendida como o momento da ponderação, da intuição com embasamento no corpus e no referencial teórico selecionados, buscando estabelecer relações, verificar contradições e compreender o fenômeno.

A coleta de dados iniciou-se por meio de informações disponibilizadas pela própria empresa, em seu website (http://www.volunteervacations.com.br), bem como artigos de revistas e jornais, casos de ensino sobre ela e seus produtos. No segundo momento, foram realizadas entrevistas, no período compreendido entre novembro e dezembro de 2015, com duas fundadoras, Maria Serra e Alice Rattan, responsáveis pelas estratégias de negócio e internacionalização da empresa. Com um total de 2 horas e 15 minutos, as duas entrevistas foram gravadas e transcritas integralmente para melhor análise dos materiais coletados. Para a coleta de dados, foi utilizado um roteiro de entrevista semiestruturado que buscou informações sobre a empresa, o contexto, sua história e seu processo de internacionalização. As diferentes 
fontes de dados permitiram uma visão sistêmica e uma triangulação de informações, validando a metodologia e auxiliando o processo analítico do trabalho.

A escolha de um estudo de caso único deu-se por ser um caso crítico e peculiar (YIN, 2005). Pelo aspecto crítico, destaca-se a sua importância no reforço e aplicabilidade da teoria do empreendedorismo internacional e da lógica do effectuation de pequenas empresas brasileiras. No quesito peculiaridade, a empresa analisada apresenta relevância por abordar o tema do empreendedorismo social internacional de forma inovadora, sendo considerada a primeira empresa do setor no Brasil com esse foco. E é exatamente pela raridade do evento (YIN, 2005), que se buscou privilegiar a compreensão dos fatores que geraram tal diferença.

Como limitações da pesquisa, pode-se compreender que, conforme afirma Zikmund (2006), a pesquisa exploratória não garante o fornecimento de evidências conclusivas necessárias para determinação abrangente de cursos de ações concretas, visando apenas, portanto, ampliar o conhecimento sobre o assunto e permitir a formulação de questões ou hipóteses.

\section{Apresentação e Análise do Caso 4.1 Da criação à internacionalização}

Fundada em abril de 2014, a VV, Volunteer Vacations, é uma empresa de empreendedorismo social. A organização possui três co-fundadores: Mariana Serra (formada em Relações Internacionais), Alice Rattan (formada em Engenharia Química) e André Fran (formado em Jornalismo e Publicidade).

Mariana Serra, além de idealizadora e co-fundadora, é CEO da VV. Ela é formada em Relações Internacionais pela ESPM, mas cursou os três primeiros períodos na Polinésia Francesa; no Taiti, fez um curso de curta duração de Criação de Negócios Inovadores no IBMEC e, atualmente, faz MBA em Gestão de Negócios no IBMEC. Recentemente, juntando sua paixão por viagens e sua alma de voluntária, Mariana participou de projetos sociais na Índia, Tailândia, Costa Rica e Tanzânia. Também trabalhou como voluntária em um orfanato no Quênia, na maior favela urbana do continente africano. Antes de fundar a VV, Mariana foi assistente do ministro Luiz Felipe Lampreia e trabalhou com Relações Institucionais na Andrade Gutierrez.

Alice, amiga e sócia da Mariana, é formada em Engenharia Química pela PUC-Rio e é mestre em Química com ênfase em Processos de Energia Renovável pelo IME. Ela tem 30 anos, como Mariana, e ocupa a posição de CFO da VV.

André Fran, co-fundador da VV, tem 35 anos e é formado em Jornalismo e Publicidade. Fran é Diretor, Escritor e Palestrante. Ele é conhecido como um dos criadores da série "Não Conta lá em Casa", do Multishow, e também colabora com O Globo, Viagem \& Turismo e com as revistas Trip, Vizoo e VICE. No programa "Não Conta lá em Casa", Fran teve a oportunidade de viajar pelos destinos mais polêmicos do mundo: Coreia do Norte, Haiti, Afeganistão, Etiópia, Kosovo, Iraque, entre outros. Nessas viagens, ele conheceu diversos projetos e organizações humanitárias.

A VV começou como um portal de turismo quando, ao se programar para uma viagem, em 2012, Mariana Serra, idealizadora da empresa, percebeu sua insatisfação com relação aos sites de pesquisa, blogs e guias de viagem. Em sua opinião, os sites de pesquisa tinham uma aparência bagunçada, e os blogs e guias de viagem impressos, em sua maioria, eram muito

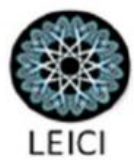


defasados. Ao chegar ao seu destino, não era incomum não encontrar o ponto turístico, restaurante, dentre outras coisas, a respeito das quais o viajante havia lido, o que tornava uma viagem, que deveria ser prazerosa, em uma experiência estressante.

Em 2013, Mariana participou da "Jornada Warren Buffett" junto ao IBMEC. Nesta Jornada, ela conheceu muitas pessoas, muitos estudantes americanos e, por isso, conseguiu expandir ainda mais sua rede de relacionamentos. Em uma conversa no evento, ela falava de uma vontade pessoal de tirar férias com propósito de voluntariado. Foi nesse momento que um desses novos contatos que Mariana fizera comentou sobre o conceito de "férias voluntárias", "volunteer vacations", que eram oferecidas por algumas agências de viagem dos Estados Unidos. A co-fundadora da VV se interessou muito pelo conceito, pois sempre esteve relacionada a projetos sociais e a ações humanitárias e, ainda, esse novo conceito era a tradução perfeita de seu desejo pessoal.

$\mathrm{Na}$ época, Mariana trabalhava como Relações Institucionais na Andrade Gutierrez e, por isso, não conseguia tirar férias por um período maior que um mês. Estava à procura, então, de algum programa social para se voluntariar durante suas férias, mas todas as instituições com as quais entrou em contato, como o "Médicos Sem Fronteiras", exigiam dedicação exclusiva. Ou seja, ela teria que se desvincular de sua profissão.

Ao voltar da "Jornada Warren Buffett", a idealizadora não conseguia tirar da cabeça o conceito de férias voluntárias que lhe haviam apresentado. Antes de qualquer coisa, ela queria experimentar esse tipo de serviço por meio de alguma empresa americana. Além disso, ela pensou que seria uma boa ideia acrescentar esse conceito ao seu portal de turismo.

O portal de turismo era dividido por tipos de viagens: "viagens a dois", "viagens em família", "viagens a negócios", entre outros. Ao visitar cada um deles, os internautas teriam acesso a dicas a respeito do que fazer e aonde ir. Sendo assim, Mariana conversou com Alice e propôs que acrescentassem mais um tipo de viagem ao portal, as "viagens voluntárias". Alice também se empolgou na hora, concordou com a ideia e demonstrou interesse em fazer uma viagem com esse propósito.

Após conhecer e conversar com Fran, Mariana repensou a sua proposta inicial de negócio e se concentrou apenas no segmento de viagens voluntárias e direcionou seus esforços para a criação da Volunteer Vacations, primeira empresa brasileira a atuar nesse nicho de mercado. Após essa conversa, Fran se tornou sócio da empresa. Os empreendedores, então, começaram a modelar o negócio, definir produtos e criar um site para a divulgação da empresa. Mariana tinha na cabeça que, se algo desse errado, eles poderiam voltar atrás com a ideia original do portal.

Atualmente, a VV tem quatro produtos a oferecer: as viagens individuais, a "Semana VV", a "Missão VV" e um produto voltado ao público corporativo.

Para as viagens individuais, os clientes da empresa podem escolher entre 12 destinos internacionais - Afeganistão, África do Sul, Costa Rica, Estados Unidos, França, Gana, Haiti, Índia, Indonésia, Quênia e Tailândia - e alguns destinos nacionais. Essas viagens são as que geram maior faturamento para a VV. Nesse caso, os clientes pagam à VV, que desenvolve um programa para capacitá-los e faz a entrega de uma experiência aos voluntários, que deverão prestar serviços sociais em outros países.

A "Semana VV" acontece sempre no exterior e tem duração mínima de uma semana. Cada edição da "Semana VV" aborda um tema diferente, como "Empreendedorismo", que foi

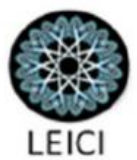


o tema da primeira edição. Esse tema é escolhido de acordo com o know-how que a empresa parceira de cada edição possui. No caso da primeira edição, a VV fez parceria com a Vem Gerir, empresa que presta consultoria para microempreendedores e empresários nas comunidades do Rio de Janeiro. Então, a VV e a Vem Gerir foram para o Quênia e, em uma semana, formaram 300 empreendedores na maior favela da África.

Ao contrário da "Semana VV", a "Missão VV" ocorre sempre no Brasil e sua duração mínima é de um dia. Para essa missão, a empresa não se prende a parcerias, ela identifica um problema em alguma comunidade no Brasil e, então, elabora uma solução para resolver o problema encontrado com os voluntários. Nesse serviço, a empresa recebe estrangeiros e brasileiros como voluntários.

O produto corporativo da VV consiste em uma capacitação oferecida a empresas que têm o objetivo de implementar o trabalho voluntário no seu escopo.

O processo de internacionalização começou em 2013, quando os sócios começaram a procurar ONGs para firmar parcerias internacionais. Mariana começou indo ao Quênia e à Tanzânia. Em 2014, ela foi para a Índia, Tailândia e Costa Rica. Em 2015, foi para os Estados Unidos.

O modelo utilizado pela VV foi baseado na experiência de uma empresa americana chamada Global Crossworld. Para conhecer o negócio e fazer o benchmark, Mariana viajou para o Quênia por essa empresa. Com essa experiência, ela pôde analisar todos os detalhes envolvidos na prestação de serviços e identificar os possíveis gaps e fontes de problemas que podem acontecer nas viagens. Tal aprendizado foi fundamental para que os empreendedores pudessem criar o negócio e evitar possíveis problemas.

O público-alvo da VV são prioritariamente jovens de 18 a 30 anos, universitários e recém-formados, de classes econômicas A e B, que gostam de viajar e já possuem experiências turísticas com os destinos tradicionais no exterior. São pessoas sensíveis e que desejam contribuir para a redução das desigualdades e a melhoria da qualidade de vida das pessoas e animais.

Atualmente a VV promove o turismo voluntário no Brasil, Estados Unidos, Chile, Costa Rica, Gana, Haiti, Índia, Indonésia, Nicarágua, Jordânia, Peru, Quênia, Tailândia e Tanzânia

As parcerias são celebradas por um MoU (Memorando de Entendimento). Nesse documento, a VV se responsabiliza por enviar voluntários capacitados por eles para a ONG, por enviar um relatório contendo a quantidade de voluntários que desejam ir, quando, o que querem fazer e até quando pretendem ficar com, no mínimo, três meses de antecedência. A ONG, em contrapartida, se responsabiliza por receber os voluntários e abrigá-los (caso disponham de alojamento), entre outros detalhes.

Em cada país, a VV tem um country manager local. Os country managers são pessoas que conhecem a região e seus costumes e, por isso, ficam responsáveis por dar auxílio aos voluntários no que precisarem, assim como por fazer o transporte do aeroporto à ONG ou ao hotel, e o inverso, quando os voluntários forem embora. Esses country managers são funcionários terceirizados e, para que a VV possa pagar a eles pelos serviços prestados, eles devem emitir um documento de transação bancária internacional, ou invoice.

Como a VV não tem uma empresa física nos países onde atua, não foram necessárias adaptações do serviço realizado em cada país. No entanto, a capacitação que eles oferecem no Brasil, antes das viagens, é um serviço que não haviam planejado, mas cuja necessidade

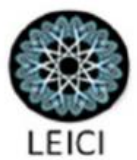


perceberam após o início de suas atividades. Esse serviço de capacitação em voluntariado foi fundamental para o sucesso da operação internacional.

A primeira venda da VV ocorreu um mês após sua abertura, em maio de 2014, e o cliente embarcou para sua jornada em julho. O destino, Washington, nos Estados Unidos, foi escolhido pelo próprio cliente.

Ainda que a VV não tenha empresa constituída no exterior, os mercados externos, especialmente quando há situações de riscos políticos, geopolíticos e ataques terroristas, são de extrema importância para sua atuação. Um terremoto, um ataque terrorista ou epidemias, por exemplo, impactam na tomada de decisão dos voluntários da VV.

O objetivo dos sócios da VV é expandir o seu escopo de atuação. Novos mercados de atuação social estão sendo planejados, como a Colômbia e o Nepal, além de outros países lusófonos, pois, apesar de o inglês ser considerado a língua internacional, ainda há muitos brasileiros que não dominam o idioma. Outra meta da VV é ampliar o número de clientes estrangeiros para que possam trazê-los como voluntários ao Brasil.

\subsection{Análise do caso Volunteer Vacations à Luz da Lógica Effectuation}

O serviço de turismo de voluntariado social, no Brasil, em 2014, constituía um novo setor, rodeado por incertezas e indefinições que exigiram dos empreendedores uma abordagem diferente de tomada de decisão para a definição de suas estratégias. A ausência de artefatos, nesse caso, setor e mercado, impossibilitou os fundadores de adotar uma lógica causal, orientada para análises e planejamentos. Ao criar a VV, os empreendedores se defrontaram com questões incertas e complexas e não possuíam objetivos pré-definidos. Essa lógica effectuation, se mostrou como o inverso da causalidade (SARASVATHY, 2001a). No caso da VV, o effectuation ocorreu quando os empreendedores iniciaram um processo de oferta de um novo produto, inovador para o Brasil, gerando, dessa forma, um novo mercado (SARASVATHY et al., 2003). Durante a entrevista, Mariana afirmou:

\footnotetext{
"Uma empresa, ela se reinventa, e como a VV, vai criando e indo com a demanda, e agora estamos botando ordem na casa, porque nem a gente esperava esse estouro que está tendo. A gente não esperava isso. A gente lançou, viu que o negócio pegou, e eu tive que pedir demissão. Eu ia pedir em agosto e acabei pedindo em junho para poder sair em julho. Enfim, era uma coisa que a gente planejou ser um portal, e aí a gente viu que dava para botar mais coisa e foi botando mais coisa. Foi dessa forma."
}

Como observado por Wiltbank e Sarasvathy (2010), a criação da oferta de valor da empresa não seguiu os princípios tradicionais de marketing com o desenvolvimento de pesquisas, definição de segmentação, público-alvo, posicionamento e o composto de marketing. Com a lógica effectuation aplicada ao marketing da VV, a estratégia surgiu a partir das vontades, conhecimentos e experiências com projetos sociais e ações humanitárias e da rede de relacionamentos dos seus fundadores. A estratégia de marketing da VV começou com a identificação do segmento de clientes desejados - jovens e jovens adultos de classes A e B, principalmente para as viagens internacionais - e a criação de parcerias locais e internacionais para a oferta dos serviços. Ao longo do tempo, foram agregados novos segmentos de clientes, como o corporativo, de forma incidental. No caso da VV, os recursos iniciais eram escassos e

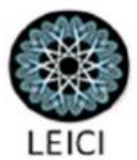


a estratégia de serviços foi construída por meio da interação com os parceiros internacionais (stakeholders) e da expansão da base de clientes, que acontece de maneira incidental.

A seguir serão apresentados os cinco princípios da lógica effectuation pela ótica da empresa objeto deste estudo, com foco em sua utilização na criação e internacionalização do negócio da Volunteer Vacations.

O primeiro princípio, intitulado começar com os meios, postula que os empreendedores devem conhecer quem eles são, ou seja, suas características, preferências e habilidades; o que possuem em termos de informações e conhecimentos (experiência anterior no setor e/ou conhecimento formal); e quem conhecem, ou seja, a rede de relacionamentos (SARASVATHY, 2001a). No caso da VV, a empreendedora e idealizadora foi Mariana, portanto as respostas dessas perguntas estão relacionadas à sua "alma" voluntária, ao seu know-how de planejamento e criação de modelos de negócios inovadores e à sua rede de relacionamentos construída nas suas viagens, no trabalho e na faculdade, respectivamente. Essas respostas foram importantes para Mariana, porque a fizeram perceber uma oportunidade gerada por algo com que ela se identificava, conhecia profundamente e tinha muitos contatos na área internacional.

O segundo princípio identificado por Sarasvathy (2001a) e compilado na escala de Chandler et al. (2011) postula que as decisões dos empreendedores, ao iniciarem um novo negócio, são tomadas com base na aceitação do risco e de perdas. O princípio do risco acessível pode ser identificado no momento em que Mariana e Alice discutiam sobre a possibilidade de investir no projeto $\mathrm{VV}$ e, de alguma forma, tentaram utilizar ferramentas como o Canvas de Negócios e a análise SWOT para definir estratégias que estivessem dentro dos limites de recursos que possuíam.

Para Sarasvhaty (2001a), o princípio da exploração de contingências se refere à capacidade de transformar o inesperado em resultados rentáveis. Segundo Tasic (2007) o empreendedor transforma contingência em oportunidade por meio da inovação. No caso da VV, a partir dos conhecimentos e rede de relacionamento dos sócios, foram criados produtos turísticos que exploravam áreas carentes e exóticas de países em desenvolvimento, destinos que geralmente não atraem turistas em férias. Nas palavras de Mariana:

Então, não interessa para o nosso consumidor se o país que ele está indo está em crise econômica ou não. O que interessa são as questões de risco político, geopolítico, ataque terrorista, que é o caso do Quênia e do Afeganistão, terremoto, que é o caso do Haiti e da Índia. Essas coisas impactam, de fato, na tomada de decisão do nosso consumidor. Se o país está mal financeiramente, é sinal de que está tudo mais barato lá. Para você levar voluntário, sai mais em conta.

O princípio de formar parcerias foi essencial para a VV. Sem as parcerias das ONGs internacionais, a empresa não poderia atuar ou, talvez, tivesse de voltar à primeira ideia, o portal de turismo. Outras parcerias, como a realizada com a empresa Vem Gerir, também foram fundamentais para a Volunteer Vacations, pois permitiram um maior escopo de produtos e, consequentemente, a diversificação dos negócios. Dentre as responsabilidades dos parceiros da VV na operação internacional, destaca-se a disponibilização dos conhecimentos sobre a cultura, condições empresariais, financeiras e políticas do mercado em que a ONG está inserida, além do fornecimento de todo o suporte para os voluntários enviados pela VV. Como mencionado por Mariana,

"para a VV atuar, a gente tem que fazer parceria com uma ONG local. Não adianta eu querer implementar uma solução de ajuda humanitária, de ajuda social, num país

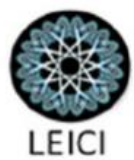


Complementa Mariana:

que eu não conheço a fundo, então é melhor eu ter uma pessoa local que sabe realmente os problemas, para poder trazer a solução adequada".

"Gana não tem nada do lado turístico, mas tem um amigo do Fran que mora lá e fala português fluente, tem vários programas sociais. Não custou nada para a gente ir para Gana. E pronto, fizemos a parceria”.

O quinto e último princípio de effectuation, segundo Sarasvhaty (2001a), é o que aceita o futuro como sendo imprevisível e incerto. Como os empreendedores não conseguem prever o futuro, suas decisões devem ser tomadas com base na experimentação, tentando dessa forma controlar o futuro ao invés de prevê-lo. No caso da VV, os empreendedores lançaram produtos e definiram perfis de clientes com base na proposição de aprender fazendo. No processo de criação e oferta de novos destinos e produtos, os empreendedores tomaram decisões com base no contexto em que se encontravam. Sobre esse princípio, Mariana comenta:

"Nossa! A gente nem pensou, a gente só foi reparando, tipo: Esse país aqui parece interessante de atuar, a ONG é interessante, tem um atrativo de férias, também. Tem o que fazer? Tem algum parque? Alguma coisa? Então legal, dá para a gente botar”.

Pode-se observar, afinal, que os cinco princípios que guiam o comportamento empreendedor, propostos pela teoria de Effectuation (SARASVATHY, 2001), estiveram presentes no momento de criação e internacionalização da VV.

\section{Considerações Finais}

O presente estudo teve como objetivo identificar o tipo de orientação que influenciou o processo de criação e internacionalização da empresa Volunteers Vacations (VV), ou seja, se houve uma orientação focada em causation ou em effectuation. Foram apresentados argumentos relacionados ao processo de internacionalização da empresa estudada, cujo foco recaía em proporcionar capacitação técnica empreendedora e promover experiências sociais por meio do serviço de voluntariado.

Após ter em mente as principais diferenças existentes entre os princípios de causation e de effectuation, mostra-se oportuna uma comparação entre as aplicações dessas estratégias na realidade da empresa em questão. Por se tratar de um caso crítico e peculiar (YIN, 2005), a opção pelo estudo de caso único se mostrou apropriada, uma vez que, a partir da raridade do campo de atuação e com base na teoria apresentada, foi possível realizar uma análise conveniente à percepção da estratégia efetivamente utilizada pela VV em seu campo de atuação - no caso a prevalência da lógica effectuation.

Percebeu-se, com a análise realizada a partir de entrevistas com os fundadores da empresa, que os cinco princípios do comportamento empreendedor, os quais fundamentam a teoria effectuation - conforme Sarasvathy (2001a) -, estiveram presentes no momento de criação e internacionalização da VV. Da mesma forma, foi também possível notar que a criação da oferta de valor da empresa não demonstrou uma preocupação em contemplar o planejamento tradicional realizado em termos de marketing, haja vista a não existência de procedimentos citados no texto, tais como o desenvolvimento de pesquisas, o processo de segmentação, a determinação do público-alvo a atender, a estruturação do posicionamento e o estabelecimento do mix de marketing. Como percebido ao longo das narrativas dos fundadores da VV, no

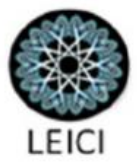


modelo effectuation aplicado ao marketing da empresa, não houve um formalismo seguido; ao contrário, ao se definir a estratégia que seria seguida, nota-se que esta emergiu das experiências e dos conhecimentos a respeito de projetos sociais e ações humanitárias que os fundadores da VV já detinham, além do proveito que foi possível tirar das respectivas redes de relacionamentos deles.

Em se tratando da utilização, pela VV, dos cinco princípios da lógica effectuation na criação e internacionalização de seu negócio, observa-se que, quanto ao princípio começar com os meios, conseguiu-se mostrar conhecimento a respeito de características, preferências e habilidades necessárias a um desenvolvimento adequado da empresa, o que facilitou a percepção da oportunidade gerada; analisando o princípio do risco acessível, ou seja, aquele que foca em uma avaliação do risco incorrido e de perdas que eventualmente ocorrerão, notase o uso de ferramentas específicas, como o Canvas de Negócios e a análise SWOT - as quais foram consideradas adequadas a fim de permitir a criação de estratégias coerentes com recursos disponíveis aos membros da empresa.

Ao se observar o princípio da exploração de contingências, ou seja, o alcance de resultados rentáveis a partir de situações imprevisíveis, a criação, pela VV, de produtos turísticos inovadores, os quais focavam em áreas carentes e exóticas de países em desenvolvimento, foi algo percebido como valoroso e elevou o interesse na empresa. Outro item que agregou valor à $\mathrm{VV}$, elevando o escopo de produtos oferecidos, foram as parcerias conseguidas com ONGs internacionais, ressaltando assim a relevância do princípio de formar parcerias.

Finalmente, a empresa mostrou estar alinhada com o princípio de controlar o futuro ao invés de prevê-lo, com decisões ocorrendo a partir da experimentação e do contexto apresentado, como se observa no lançamento de produtos e na definição de classes de clientes por meio do "aprender fazendo".

Assim, com os cinco princípios efetivamente presentes, comprova-se o uso da lógica effectuation no caso estudado, o qual pode servir de base para outras empresas em situação similar ou que estejam vivenciando experiências parecidas com aquelas apresentadas na realidade da VV.

\section{Referências}

ANDERSSON, S. International entrepreneurship, born globals and the theory of effectuation. Journal of Small Business and Enterprise Development, v. 18, n. 3, p. 627-643, 2011.

BARDIN, I. Análise de conteúdo. Lisboa: Edições Setenta,1994.

CASSON, M.; WADESON, N. The discovery of opportunities: Extending the economic theory of the entrepreneur. Small Business Economics, v. 28, n. 4, p. 285-300, 2007.

CHANDLER, G.N. et al. Causation and effectuation processes: A validation study. Journal of business venturing, v. 26, n. 3, p. 375-390, 2011.

DELlAGNELO, E. H. Livramento; SILVA, Rosimeri Carvalho. Análise de conteúdo e sua aplicação em pesquisa na administração. Pesquisa qualitativa em administração: teoria e prática, v. 1, p. 97-118, 2005. 
FRESE, M. et al. Towards a psychology of entrepreneurship - an action theory perspective. Foundations and Trends ${ }^{\circledR}$ in Entrepreneurship, v. 5, n. 6, p. 437-496, 2009.

FISHER, G. Effectuation, causation, and bricolage: A behavioral comparison of emerging theories in entrepreneurship research. Entrepreneurship theory and practice, v. 36, n. 5, p. 1019-1051, 2012.

GROSS, M.J.; BROWN, G. An empirical structural model of tourists and places: Progressing involvement and place attachment into tourism. Tourism management, v. 29, n. 6, p. 1141$1151,2008$.

HONIG, B.; KARLSSON, T. Institutional forces and the written business plan. Journal of Management, v. 30, n. 1, p. 29-48, 2004.

KUZNETS, S.; MURPHY, J.T. Modern economic growth: Rate, structure, and spread. New Haven: Yale University Press, 1966.

MCGEHEE, N. G.; CLEMMONS, D.; LEE, S. Voluntourism Survey Report. 2008.

READ, S.; SARASVATHY, S. D. Knowing what to do and doing what you know: Effectuation as a form of entrepreneurial expertise. The Journal of Private Equity, p. 45-62, 2005.

MEYER, J.W.; ROWAN, B. Institutionalized organizations: Formal structure as myth and ceremony. American journal of sociology, v. 83, n. 2, p. 340-363, 1977.

PORTER, M.E. Competitive strategy: Techniques for analyzing industries and competition. New York, v. 300, p. 28, 1980.

READ, S.; SARASVATHY, S.D. Knowing what to do and doing what you know: Effectuation as a form of entrepreneurial expertise. The Journal of Private Equity, p. 45-62, 2005.

SARASVATHY, S.D. What makes entrepreneurs entrepreneurial?. 2001.

SARASVATHY, S.D Causation and Effectuation: Towards a theoretical shift from economic inevitability to entrepreneurial contingency. Academy of Management Review. V. 26, p. 243 288. 2001a.

SARASVATHY, S.D. Effectual reasoning in entrepreneurial decision making: Existence and bounds. Best paper proceedings, Academy of Management 2001. Washington, p. 3-8, 2001b.

SARASVATHY, S.D. et al. Three views of entrepreneurial opportunity. In: Handbook of entrepreneurship research. Springer, Boston, MA, p. 141-160, 2003.

SARASVATHY, S. et al. An effectual approach to international entrepreneurship: Overlaps, challenges, and provocative possibilities. Entrepreneurship Theory and Practice, v. 38, n. 1, p. 71-93, 2014.

TASIC, I.A.B. Estratégia e empreendedorismo: decisão e criação sob incerteza. 2007. Tese de Doutorado.

WILTBANK, R. E.; SARASVATHY, S. D. What effectuation is not: Further development of an alternative to rational choice. In: Academy of Management Conference, Batten Institute at the Darden Graduate School of Business, Virginia, EUA. 2010. 
YIN R.K. Estudo de caso: Planejamento e métodos. Porto Alegre, 2005.

ZIKMUND, W.G. Princípios da pesquisa de marketing. São Paulo: Pioneira Thomson Learning, 2006.

.

